\title{
On the Construction of Evaluative Meanings in English Tourist Discourse from the Perspective of Graduation System
}

\author{
Ning Kang \\ School of Foreign Languages, Qingdao University of Science and Technology, Qingdao, P.R. China \\ kangningkn@163.com
}

Keywords: tourist discourse; evaluative meanings; Graduation system; Appraisal Theory

\begin{abstract}
Set in the framework of Graduation system in Appraisal Theory, this article focuses on the employment of Graduation resources in English tourist discourse, aiming at finding how evaluative meanings are graded. The findings suggest that, of the two major sets in Graduation system, more resources for Force are employed than for Focus in tourism English. That is, English tourist discourse tend to scale the degree or amount of the evaluative meanings. Further study shows that, within Force, there are more Intensification resources than Quantification resources; whereas within Force, English tourist discourse tends to employ more sharpening than softening resources. Through revealing the features and ways of how Graduation resources are employed in tourist English, it is hoped that this study can help to effectively write as well as translate tourist discourse.
\end{abstract}

\section{Introduction}

Tourist discourse, which is a production of tourism industry, is persuasive in nature, aiming to promote tourism products and services. The language of tourist discourse abounds in evaluative meanings and Graduation resources. The present study is set in the framework of Graduation system in Appraisal Theory, in which the Graduation system is about how the writer/speaker graduates the intensity or the force of the evaluative (or attitudinal) meanings. This system is also concerned with the graduation of the focus of the semantic categorizations. This study is based on the self-compiled Tourism English Corpus (TEC) with an approach of quantitative analysis in combination with qualitative discussions. This research attempts to find out the distribution features of Graduation resources in English tourist discourse, how these resources are realized linguistically, and how such resources help leverage the promotion effects. It is hoped that this study can help to effectively write as well as translate tourist discourse.

\section{Appraisal Theory and Its Graduation system}

Appraisal theory is developed within Systemic Functional Linguistics by Martin and White et al, who are representatives of neo-Hallidayan School. With a purpose of construing interpersonal meaning, this theory focuses on "the kinds of attitudes that are negotiated in a text, the strength of the feelings involved and the ways in which values are sourced and readers aligned" [1]. There are three interacting subsystems within this system: Attitude, Engagement and Graduation, which can be applied to study evaluative meanings in a variety of discourses. Attitude concerns "our feelings, including emotional reactions, judgments of behavior and evaluation of things" [2]. Engagement system is about sourcing attitudes and contains the resources that speakers/writers use to express their interpersonal positioning in discourse. The system of Graduation deals with such resources that are used to strengthen or weaken attitudinal meanings.

Appraisal theory has been applied in many studies to analyze different types of discourse. For example, it is used to explore the texture of an editorial, how the editor negotiates solidarity with readers [3]. Matruglio [4] carries out an Appraisal analysis of the rationales and value statements in the discipline of history in Australian senior high schools, analyzes how a complex interplay of judegement and appreciation is constructed. Peng Xuanwei [5], a Chinese scholar, applies Appraisal system to explore literary texts, attempting to establish a framework of Appraisal Stylistics, a new discipline within Functional Stylistics. 
The system of Graduation can be further divided into two categories - Force, which strengthens or weakens the degree of Attitude, and Focus, which sharpens or softens the boundaries between categories of the non-gradable items. Fig. 1 demonstrates the network of Graduation.

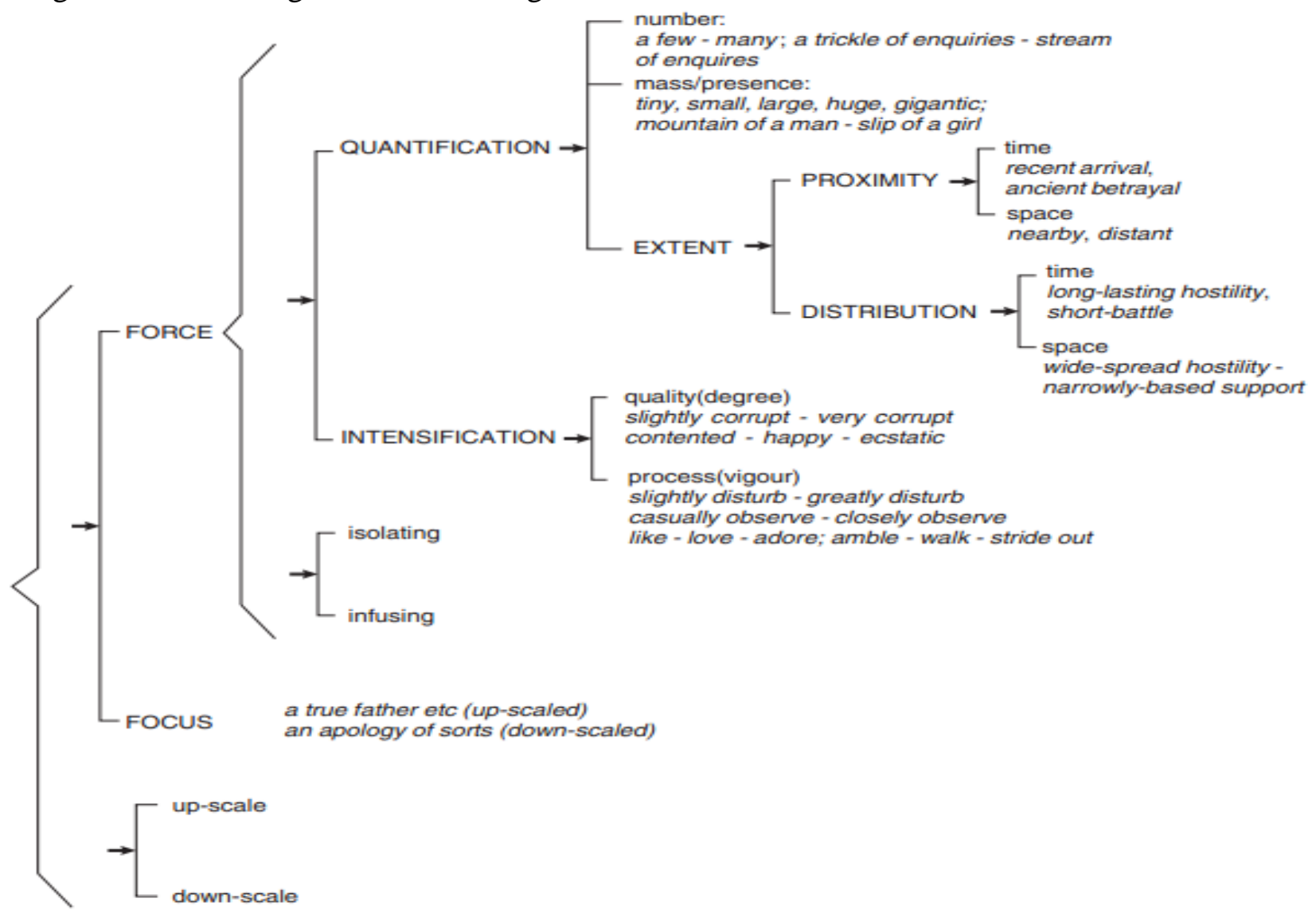

Fig. 1. The network of Graduation system

Though many studies apply the subsystems of Attitude and Engagement to analysis of different discourses, there are very few researches on Graduation system. Susan and Martin [6] investigates the role of Graduation in academic discourse, focusing on how academic writers/speakers adjust expressions of attitude by grading up or grading down. Fu Xiaoli and Fu Tianjun [7] analyze the Graduation resources in literary texts, and find that the frequent use of Graduation is related to topics. Dong Min's study is set in the framework of Graduation, looking at the interpersonal meanings in the debate discourse produced at an American Congress [8]. She finds that Graduation resources can be applied to grade the attitudinal and engagement meanings in debate utterances, thus helping debaters to expound and express their stance.

To make up for the inadequate studies on Graduation resources, the present research is informed by the system of Graduation, with an attempt to explore Graduation resources in English tourist discourse.

\section{Research Methodology and Tools}

This study is based on a self-compiled corpus - Tourism English Corpus (TEC). The corpus texts were collected from websites promoting tourism products and service in major English speaking countries. Most of the websites are run by government departments, travel agencies or the managements of scenic destinations. The texts in my corpus concentrate on those that introduce towns and villages, accommodations, natural attractions, and cultural events. Table 1 presents the data of the corpus.

Since the study focuses on investigating the Graduation resources in tourism English, the corpus CTE is annotated with Graduation features. There are 9 such features being annotated as shown in the following Table 2. 
Table 1. Data of TEC

\begin{tabular}{c|c|c}
\hline Text types & Number of texts & Number of word tokens \\
\hline cities \& villages & 120 & 98167 \\
\hline natural scenery & 120 & 93354 \\
\hline accommodations & 180 & 61656 \\
\hline Cultural events & 180 & 68870 \\
\hline total & 600 & 322047 \\
\hline
\end{tabular}

Table 2. Graduation features annotated in TEC

\begin{tabular}{c|l|c}
\hline Feature No. & Feature description & Tag \\
\hline Feature 1 & Force: up-scale & [up] \\
\hline Feature 2 & Force: down-scale & [down] \\
Feature 3 & Force: Quantification-number & [quan: num] \\
\hline Feature 4 & Force: Quantification-mass & [quan: mass] \\
\hline Feature 5 & Force: Quantification-extent & [inten: qual] \\
\hline Feature 6 & Force: Intensification-quality & [inten: proc] \\
\hline Feature 7 & Force: Intensification-process & [shar] \\
\hline Feature 8 & Focus: Sharpen & [sof] \\
\hline Feature 9 & Focus: Soften & \\
\hline
\end{tabular}

The 9 features were added to TEC with the aid of The UAM CorpusTool. The tool allows the user to annotate corpus files at different linguistic layers, which can be defined by the user. We defined two layers in this study - one for identifying text types in the corpus and the other for analyzing Graduation resources. Hence, two coding schemes were created to describe and assign these linguistic features to the texts in TEC. The UAM CorpusTool is an ideal instrument for my study in that it has a powerful statistical function. It not only performs general statistics of text features, such as the total number of annotated segments, but also offers statistics of the particular features defined in the scheme.

\section{Results and Discussion}

\section{General features of Graduation in TEC}

As discussed in above sections, Graduation is designed for adjusting how to grade attitudinal meanings in discourse, to increase or decrease. There are two subsystems within it - Force and Focus. The former has to do with grading such attitudinal meanings as can be intensified or quantified; the latter concerns sharpening or softening unscalable categories of people and things when viewed from an experiential perspective. Table 3 shows the general use of Graduation resources in TEC.

Table 3. General distribution of Graduation resources in TEC

\begin{tabular}{c|c|c}
\hline Resources & Frequencies & Proportion (\%) \\
\hline Force & 1881 & 77.2 \\
\hline Focus & 556 & 22.8 \\
\hline total & 2437 & 100 \\
\hline
\end{tabular}

As we can see from the table, the two types of Graduation resources distribute unevenly in the corpus, in which resources for Force account for a much larger proportion than those for Focus. It seems to suggest that writers of tourism English prefer intensifying the degree of or quantifying the amount of the attitudinal meanings constructed in tourist discourse, rather than sharpening or 
softening category distinctions. The following sections will report the detailed usage of Graduation resources in English tourist discourse.

\section{Force: Intensification vs. Quantification}

There are two subsets within Force resources - Intensification and Quantification. The former assesses the degree of intensity whereas the latter assesses the degree of amount. Table 4 presents the distributions of the two subsets in TEC.

Table 4. Distribution of Force resources in TEC

\begin{tabular}{c|c|c}
\hline Resources & Frequencies & Proportion (\%) \\
\hline Intensification & 1159 & 61.6 \\
\hline Quantification & 722 & 38.4 \\
\hline total & 1881 & 100 \\
\hline
\end{tabular}

As shown in Table 4, more Intensification resources are used in TEC; that is, tourism English writers tend to impress readers through assessing the intensity degree rather than amount. This suggests that Intensification is a more effective meaning to promote tourism resources.

In assessing the intensity degree, resources for Intensification operate over two aspects: qualities and processes, as shown in Fig. 1. Through further investigation, it is found that tourism English applies most of the Intensification resources to assess qualities, with only a few for assessing processes. This may be explained by the fact that tourist texts mainly deals with descriptions of certain tour destinations.

In assessing the degree of amount, resources for Quantification operate around three aspects: number, mass/presence and extent. We found that the majority of resources for Quantification in tourism English are used to assess the extent with only a few for mass/presence and number.

Force: upscale vs. downscale

Generally, attitudinal meanings can either scale up or down, which expresses the speaker/writer's positiveness or negativeness. Both Intensification and Quantification within Force interact with Attitude to either volume up or down some particular attitude.

Table 5. Scaling of Force resources in TEC

\begin{tabular}{c|c|c}
\hline Resources & Frequencies & Proportion (\%) \\
\hline Up-scaling & 1490 & 79.2 \\
\hline Down-scaling & 391 & 20.8 \\
\hline total & 1881 & 100 \\
\hline
\end{tabular}

Table 5 suggests that the up-scaling of Force resources is more prominent than down-scaling in tourism English. This feature conforms to the promotional nature of tourist discourse. Scaling up the Intensification and Quantification resources can help definitely to enhance the promotional effects as it produces positive impressions. However, it should be noted that down-scaling of Force resources does not necessarily reduce the promotional effects; in fact many cases show that down-scale wording can be more objective and trustworthy.

Focus: Sharpen vs. Soften

As has been discussed, Focus deals with grading the experientially non-gradable categories. These categories can be either sharpened to highlight their prototypicality or the preciseness, or be softened to limit marginal memberships in the category. We have noted from Table 3 that Focus is not a preferred option of Graduation resources in tourism English with only 556 instances. 
Table 6. Distribution of Focus resources in TEC

\begin{tabular}{c|c|c}
\hline Resources & Frequencies & Proportion (\%) \\
\hline Sharpening & 477 & 85.8 \\
\hline Softening & 79 & 14.2 \\
\hline total & 556 & 100 \\
\hline
\end{tabular}

Table 6 shows that tourism English employs a large majority of sharpening resources, compared with softening resources. In tourism English, the sharpening wording functions to create positive assessment, hence making readers become more interested in what has been described. In TEC, the most commonly used sharpening wording are real, really, true, truly, genuine, authentically, original, exact, pure, precisely, sheer and definitely. Different from the function of sharpening, softening wording commonly "flags a negative assessment" [9]. However, the sharpening wording in English tourism discourse does no show much negative assessment; in most cases, it remains neutral, sometimes positive.

\section{Conclusion}

This study was conducted, taking the Graduation system within Appraisal theory as its analytical framework. It has been proved that this framework is effective and applicable to explore Graduation resources in tourist discourse. Applying this framework, the ways how tourism writers assess the degree of the intensity or the amount in the attitudinal meanings have been revealed. The present study also shows that it is at once beneficial and possible to combine a corpus-based quantitative research with qualitative analysis within Graduation system. The findings of this study are instructive to effective writing of English tourist texts as they enable tourism English writers to employ correctly the Graduation resources to construct attitudinal meanings and align with readers, and so to enhance the promotional effects.

\section{Acknowledgement}

This paper has been sponsored by the research project (No. 12WG23) of Education Department of Shandong Province (China)

\section{References}

[1] J. R. Martin, D. Rose, Working with Discourse: Meaning beyond the Clause (2nd edition). London: Continuum. pp. 25, 2007.

[2] J. R. Martin, P. R. R. White, The Language of Evaluation: APPRAISAL in English. London: Palgrave MacMillan. pp. 35, 2005.

[3] J. R. Martin, "Mourning: how we get aligned", Discourse \& Society, Vol. 15, no. 2, pp. 321, 2004.

[4] E. Matruglio, "Values and Attitudes in Ancient and Modern History", in Bridging Discourses: ASFLA 2007 Online Proceedings, 2007.

[5] X. W. Peng, "Study on Engagement and Graduation in Chinese", Contemporary Foreign Language Study, vol. 10, pp. 55-62, 2010.

[6] S. Hood, J. R. Martin, " Invoking attitude: The play of graduation in appraising discourse," Revista Signos, vol. 38, no. 58, pp. 195-220, 2005. 
[7] X. L. Fu, T. J. Fu, "Analysis of Graduation System in English Literary Discourse," Journal of Hebei Normal University (Philosophical and Social Science Edition), vol. 32, no. 3, pp. 115-119, 2009.

[8] M. Dong, "Analysis of interpersonal meanings in debate discourse from the perspective of Graduation system," Journal of Foreign Language Study, no. 3, pp. 14-20, 2012.

[9] A. Nakamura, " Construction of evaluative meanings in IELTS writing: an intersubjective and intertextual perspective," $\mathrm{PhD}$ degree of Faculty of Education, University of Wollongong, 2009. 